\title{
Oil Cooler Selection for Hydraulic System of Plastic Injection Moulding Machine: A Review
}

\author{
Sandip Kumar Das ${ }^{1}$, Kedar Bhojak ${ }^{2}$ \\ ${ }^{1}$ PG Student, Mechanical Engineering Department, L.D.R.P-I.T.R, Gandhinagar, Gujarat, India \\ ${ }^{2}$ Professor, Mechanical Engineering Department, L.D.R.P-I.T.R, Gandhinagar, Gujarat, India
}

\begin{abstract}
The effect of oil temperature of the hydraulic system for Plastic Injection Moulding Machine is studied in this paper. Traditionally in India the hydraulic oil VG-68 for Plastic Injection Moulding Machine is used, which has an optimum temperature range with desired effective viscosity property is between $40^{\circ} \mathrm{C}$ to $50^{\circ} \mathrm{C}$. The oil temperature goes high up to $55^{\circ} \mathrm{c}$ and even higher than that during summer, which is not desirable for the machine operations. It is found that the operation of the machine will get sluggish as the oil viscosity get decreases. This is due to continuous flow and heavy production schedule. The oil needs to be cooled down as fast as possible from the elevated temperature to required temperature. So it is very important to choose the correct type and size of oil cooler for hydraulic system.
\end{abstract}

Keywords: Hydraulic system, VG-68, Plastic Injection Moulding Machine, Viscosity Grade oil, Heat Transfer Rate Increments, oil cooler

\section{Introduction}

In present scenario, where the plastic components are in more demand to replace the metal components in need of making the system low weight and cost effective, the demand of plastic injection moulding machine is also increased. However there is an option of Electric powered plastic injection moulding machine is available but hydraulic powered is more popular for its initial and maintenance costs, which uses viscosity grade oils according to the needs. Various viscosity grades of hydraulic oil for the hydraulic system of Plastic Injection Moulding Machine are available. For the IMM, selection of viscosity grade (VG) oil plays an important role. And retention of that viscosity is even more important for the working of the hydraulic system for plastic injection moulding machine.Hassani et al. [1]concluded that the hydraulic oil which passes through any orifice produces heat. The factor which produces heat are pressure valves, relief valves, pipes with small diameters, dirty filters, internal leakage in the hydraulic system and friction. The hydraulic system in Plastic Injection Moulding Machine consists of circuits to accomplish various task in cylinders like mould clamp cylinder, retraction cylinder, injection cylinder, auxiliary cylinder etc[7] Every of these circuits causes temperature rise because of pressure drop due to the resistance of the circuit comprising ingredients against fluid flow, the existence of throats (contracting) on the fluid passage and so on while the hydraulic system is working. For that selection of propertype and size of oil cooler for hydraulic system is very important and that is discussed in next headings.

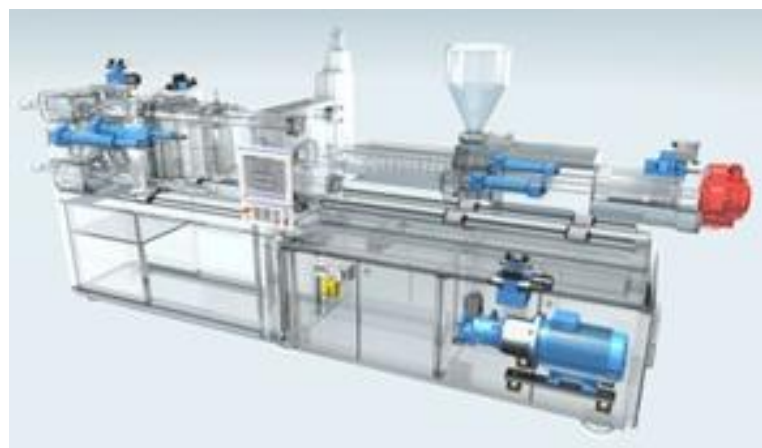

Figure 1: Schematic of hydraulic system in IMM [05]

\section{Selection of cooler (Heat Exchanger)}

Heat generation destroys hydraulic system for that hydraulic oil coolers are widely used for keeping the hydraulic oil temperature under its limits. Hydraulic oil cooler removes the excessive heat, which is generated by the energy loss in the hydraulic system as well as that from the external sources such as furnaces, engines, and even the surrounding environment. To design temperature optimized hydraulic systems, coolers are often used to keep the oil temperature within the limits. For cost efficient operation which provides a number of performances, environmental and economical benefits, such circuits are basic prerequisites. Benefits like:

- Maintaining the correct temperature keeps oil at its recommended viscosity, ensuring mechanical components are properly lubricated and hydraulic devices run at peak efficiency. Letting oil temperature rise beyond recommended limits can reduce the life of a system due to poor lubrication, higher internal leakage, a higher risk of cavitations, and damaged components.

- Keeping temperatures down also helps ensure the oil and other components last longer. Excess heat can degrade hydraulic oil, form harmful varnish on component surfaces, and deteriorate rubber and elastomeric seals.

- Operating within recommended temperature ranges increases a hydraulic system's availability and efficiency, improving equipment productivity. 


\section{International Journal of Science and Research (IJSR) \\ ISSN (Online): 2319-7064 \\ Index Copernicus Value (2013): 6.14 | Impact Factor (2015): 6.391}

- Finally, with more machine uptime and fewer shutdowns, it reduces service and repair costs.

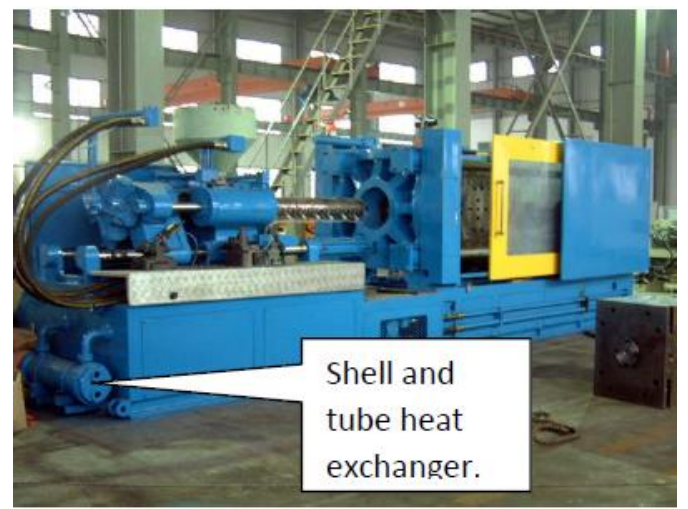

Figure 2: Injection moulding machine using shell and tube type of heat exchangers

Apart from the benefits of the cooler, it is important to select the proper size of the cooler because under sized cooler will allow oil temperature higher than the recommendations and oversized cooler also effects bad to the system efficiency by reducing the temperature below the recommended range. Oversized coolers also cost higher. So it is vital to select proper size of hydraulic cooler depending upon their applications.

\section{Cooler Types and Selection}

In order to achieve optimum process operations, it is essential to use the right type of process equipment in any given process. Heat exchangers, commonly used to transfer energy from one fluid to another, are no exception. The selection of the proper type of cooler is of critical importance. Selecting the wrong type can lead to suboptimum plant performance, operability issues and equipment failure.

The following criteria can help in selecting the type of heat exchanger best suited for a given process:

- Application (i.e. sensible vapour or liquid, condensing or boiling)

- Operating pressures \& temperatures (including start up, shutdown, normal \& process upset conditions)

- Fouling characteristics of the fluids (i.e. tendency to foul due to temperature, suspended solids ...)

- Available utilities (cooling tower water, once through cooling water, chilled water, steam, hot oil...)

- Temperature driving force (i.e. temperature of approach or cross and available LMTD)

- Plot plan \& layout constraints

- Accessibility for cleaning and maintenance

- Considerations for future expansions

- Mechanical considerations such as: 1) material of construction; 2) thermal stresses (during start up, shutdown; process upset and clean out conditions); 3) impingement protection

Shell-and-tube heat exchangers accounts for more than 50\% of all heat exchangers installed. However, in many cases, there are more attractive alternatives in terms of cost and energy recovery. Any time a heat exchanger is being replaced, the opportunity should be taken to re-assess if the type used is best for the given process. Operating changes since initial installation as well as advancements in the field of heat transfer may point towards a different type as being optimal.

\section{Cooler Options}

Several different types of coolers are suitable for hydraulic systems, with air and water cooled being the most common.

\section{(a) Water Cooling:}

Shell-and-tube heat exchangers have an outer-flanged shell with end bonnets appropriately sealed to the shell ends. A precise pattern of tubing within the shell and terminates in end plates. Tube ends are fastened to the end plates, which seal each end of the shell. Cool water flows inside the tubes, and hot hydraulic oil flows around the tubes within the shell.

These heat exchangers are made of red brass, copper, cast iron, admiralty brass, stainless steel, aluminium, or other special metals. The tubes that make up the tube bundle, or core, are arranged in geometric tube bundle patters, (square or triangular centreline spacing when viewed from the tube ends) to help promote turbulent flow.

The tubes run through a number of baffle plates that provide structural rigidity and create a maze through which the hot fluid must flow. This flow pattern enhances heat transfer by forcing the hot fluid to flow perpendicular to the tube and promoting laminar flow. Many tube bundles are permanently sealed in the shell. Models with removable tube bundles are more expensive and have different sealing conditions at the shell ends.

\section{(b) Air Cooling:}

When the air sink is chosen to receive waste heat, a radiator is used. Even though it radiates heat only to a small degree, it is rarely called a convector.

Hot oil passes through the tubes of these heat exchangers and tabulators help break up laminar flow to promote efficient heat transfer from the fluid to the tube wall. The tube metals also have high tube wall. The tube metals also have high thermal conductivity. Stagnant air around tube exteriors presents a problem in the effort to increase heat transfer. Still air is a poor conductor and has a high thermal resistance that limits heat transfer. Increasing air flow over the tubes helps decrease this thermal resistance. The amount of decrease again depends on whether the air flow is laminar or turbulent. In either case, the air still inhibits heat transfer because it is not as good a conductor of heat as water or oil.

As with shell-and-tube heat exchangers, increasing the heat transfer surface area increases heat transfer capacity. Fins, physically fastened to the tubes, increase surface area and as an added benefit, help break up laminar air flow.

Considerations that help determine heat exchanger core configurations are:

- Oval tubes promote turbulent flow at a lower flow rates than round tubes.

- Round tubes give higher flow rates and lower pressure drops than with oval tubes. 


\section{International Journal of Science and Research (IJSR) \\ ISSN (Online): 2319-7064 \\ Index Copernicus Value (2013): 6.14 | Impact Factor (2015): 6.391}

- Materials generally are admiralty brass, brass, aluminium, or steel. Choice can depend upon structural needs or service environment, and

- Fins vary in heat transfer capability and cleanability. Fin types are flat plate, humped, and louvered, ranked in order of increasing ability to generate turbulent flow and in decreasing order of cleanability.

\section{(c) Newer Designs:}

Shell-and-tube heat exchangers have been the mainstay of industry for more than 50 years. Newer designs have been developed to increase effectiveness, provided equivalent heat transfer surface in a smaller envelope, and reduce cost.

The extended-surface design adds many fins to the external sides of tubes. These fins provide more surface area and improve the heat transfer coefficient, thereby reducing the size of the heat exchanger over standard shell-and-tube versions. However, because of the greater internal heattransfer surface area, pressure drop is correspondingly greater than in the older versions.

The extended-surface shell-and-tube heat exchanger is also available with a spring-loaded pressure surges, a bypass valve opens to protect the tubes from damage due to excess pressure.

Another newer heat exchanger design is the brazed-plate type. The heat-transfer surface consists of a series of stainless-steel plates, each stamped with a corrugated pattern designed for a combination of high strength, efficiency, and fouling resistance. The number and design of the plates vary according to the desired heat-transfer capacity. The plates are stacked together with thin sheets of copper or nickel between each plate. The plate pack, end plates, and connections are brazed together in a vacuum furnace to secure the plates together at the edges and at all contact points. Inlet and outlet connections are available in a number of different styles.

The brazed-plate heat exchanger is compact, rugged and provides high heat transfer capability. Its heat-transfer surface area is concentrated in a very small volume. The corrugations in the plates induce turbulent flow to increase heat transfer and reduce fouling. A brazed-plate heat exchanger holds about one-eighth the liquid volume of a thermally comparable shell-and-tube counterpart.

Normally the hot and the cold fluids make only one pass through this exchanger. The incoming fluids are directed through alternate parallel channels created by the stacked channel plates. The single pass through the unit means the flow passage is as long as the heat exchanger is high. This short flow path offsets any pressure drop which is caused by the turbulence.

The same heat-transfer principles govern performance of brazed-plate heat exchangers. Stainless steel construction of the brazed-plate design allows flow velocities as high as $20 \mathrm{ft} / \mathrm{sec}$. These higher velocities, coupled with turbulent flow, provide heat-transfer rates of three to five times those of shell-and-tube heat exchangers. The higher heat transfer rate means less area is required for a given capacity. Tests show the brazed-plate design can handle particles up to about 0.040 in. without plugging. A strainer should be used if larger particles may be encountered. Because of their construction, these heat exchangers must be cleaned chemically rather than mechanically.

The plate-fin heat exchanger is characterized by its compact light-weight, efficient design. It provides significantly more cooling per cubic inch than the other designs described earlier. Plate-fin heat exchangers consist of finned chambers separated by flat plates and route fluids through alternating hot and cold passages.

Heat is transferred via fins in the passageways, through the separator plate, and into the cold fluid via another set of fins. Construction consists of alternate layers of fins and plates brazed together to provide a honeycomb structure that offers high resistance to vibration and shock. They are frequently used in military and aviation applications.

Finned passage sizes are easily varied by changing fin heights. The number and width of finned passages are also easily varied as is the fin destiny. A plate-fin heat exchanger size can be customized to fit a particular envelope.

The plate-fin heat exchanger usually is fabricated from aluminium, but regardless of the materials of construction, the core is furnace brazed in a controlled atmosphere or high vacuum. Because plate-fin heat exchangers require more precise manufacturing, they are usually more expensive than other designs.

\section{Application Data}

The next step is collecting suitable application data such as maximum system temperature, fluid-flow rate, type of fluid to be cooled, the heat load and maximum allowable pressure drop of the cooled fluid after selecting the type of cooler.

Determining heat load is essential. Many users assume efficiency for their system, and then derive the heat load. For example, if operating under the premise that a system is $70 \%$ efficient, one can assume the remaining $30 \%$ of input power is the heat load. Estimating overall system efficiency produces a heat load figure, but calculating heat load is generally more accurate.

One analytical method involves measuring all pressure losses and flow rates in the system, which, in most cases, is not practical. Another, simpler method measures reservoir temperature over a given period of time. By monitoring reservoir temperature and knowing the type and volume of fluid, heat load, Q, can be calculated using:

$$
Q=\frac{\Delta T x c_{p} x \rho x V}{t}
$$

Where $\Delta T=$ rise in temperature; $c_{p}=$ specific heat; $\rho=$ fluid density; $V=$ total fluid volume, and $t=$ time.

The more accurate the system data, the better one can gauge required cooler size. After calculating heat load, engineers 


\section{International Journal of Science and Research (IJSR) \\ ISSN (Online): 2319-7064 \\ Index Copernicus Value (2013): 6.14 | Impact Factor (2015): 6.391}

may apply a correction or "safety" factor to account for uncertainties. Whether or not to use one depends upon how conservative the design needs to be and the level of confidence in the data. More likely, engineers inadvertently apply a safety factor when determining the cooling-fluid temperature (the ambient air temperature for air-cooled oil coolers or water temperature for water-cooled oil coolers). That is, calculations often use an ambient air temperature of $40^{\circ} \mathrm{C}$ or higher, and water temperature is often set at or above $30^{\circ} \mathrm{C}$. In reality, fluid temperatures are rarely this high.

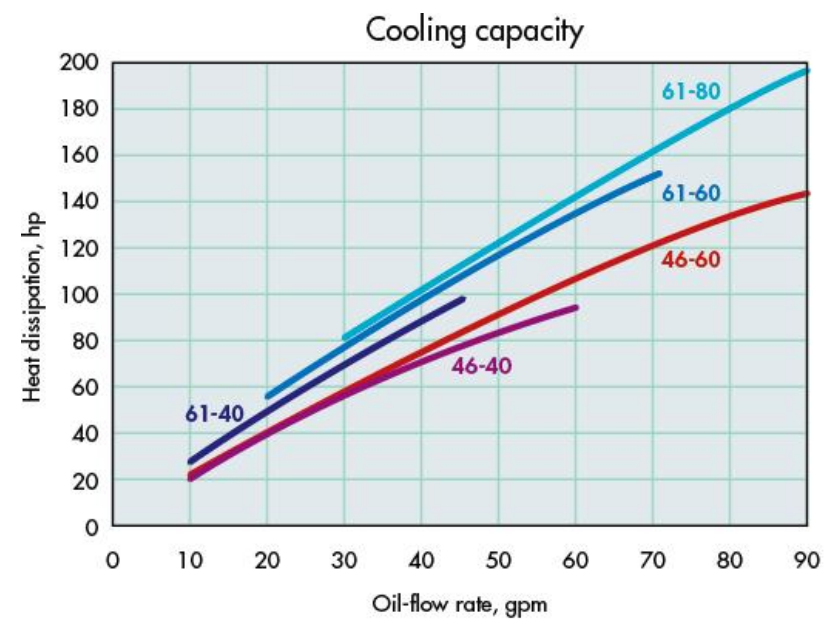

Figure 3: The graphs show cooling capacity for Parker OAW Model 46 and 61 water-type coolers

Another consideration is whether the cooler will be plumbed in the return line or in an off-line recirculation loop. It can make a big difference. Sizing coolers installed in return lines is rather straightforward. Coolers can either be sized using maximum system temperatures or maximum reservoir temperatures. Oil temperature entering the cooler is the system temperature, and oil temperature exiting the cooler is the reservoir temperature.Sizing off-line coolers can be much more complicated, depending on pump inlet location in relation to the return-line outlet, and whether or not there are any baffles between the two.

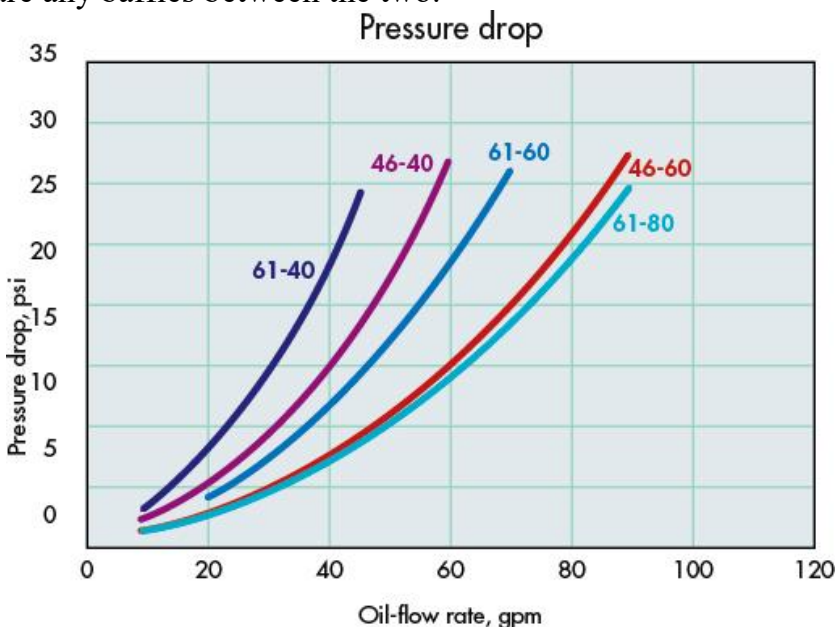

Figure 4: The graphs show pressure drop for Parker OAW Model 46 and 61 water-type coolers

In a worst-case scenario, the cooler is sized such that inlet temperature to the cooler matches the required reservoir temperature. This means oil exiting the cooler is colder than the desired reservoir temperature. But this cold oil mixes with hot return-line oil that has not been cooled at all Mixing the two sources of oil, along with the locations of the oil lines relative to each other, complicates modelling of actual reservoir conditions.

Past experience, is always the best place to start to guide the selection of heat exchanger types. Understanding the reasons behind both successes and failures will lead to better equipment selection. When comparing different types of heat transfer equipment, one must take into consideration the total cost of the equipment which includes:

- purchase cost

- installation cost

- Operating cost (pumping, fan...)

- maintenance cost

In order to make the best selection, it is important to have some knowledge of the different types of heat exchangers and how they operate. The tables below offer the advantages and disadvantages of common types of heat exchangers. They can be used to arrive at a type that is best suited for a given process.

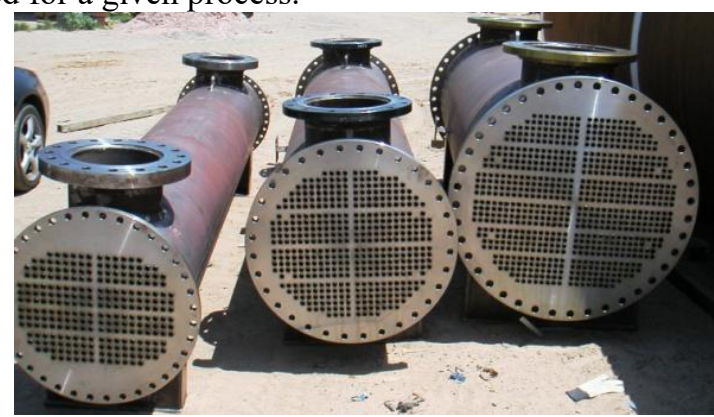

Figure 5: Shell and tube heat exchanger [2]

Table 1: Advantages and Disadvantages of shell and tube heat exchanger

\begin{tabular}{|c|c|}
\hline \multicolumn{2}{|c|}{ Shell \& tube heat exchangers } \\
\hline Advantages & Disadvantages \\
\hline $\begin{array}{c}\text { Widely known and } \\
\text { understood since it is the } \\
\text { most common type }\end{array}$ & $\begin{array}{c}\text { Less thermally efficient than other } \\
\text { types of heat transfer equipment }\end{array}$ \\
\hline $\begin{array}{c}\text { Most versatile in terms of } \\
\text { types of service }\end{array}$ & $\begin{array}{c}\text { Subject to flow induced vibration } \\
\text { which Can lead to equipment failure }\end{array}$ \\
\hline $\begin{array}{c}\text { Widest range of allowable } \\
\text { design pressures and } \\
\text { temperatures }\end{array}$ & $\begin{array}{c}\text { Not well suited for temperature cross } \\
\text { conditions (multiple units in series } \\
\text { must be used) }\end{array}$ \\
\hline $\begin{array}{c}\text { Rugged mechanical } \\
\text { construction - can } \\
\text { withstand more abuse } \\
\text { (physical and process) }\end{array}$ & $\begin{array}{c}\text { Contains stagnant zones (dead zones) } \\
\text { on the shell side which can lead to } \\
\text { corrosion problems }\end{array}$ \\
\hline \multicolumn{2}{|c|}{$\begin{array}{c}\text { Subject to flow mal-distribution } \\
\text { especially with two phase inlet } \\
\text { streams }\end{array}$} \\
\hline
\end{tabular}




\section{International Journal of Science and Research (IJSR) \\ ISSN (Online): 2319-7064}

Index Copernicus Value (2013): 6.14 | Impact Factor (2015): 6.391

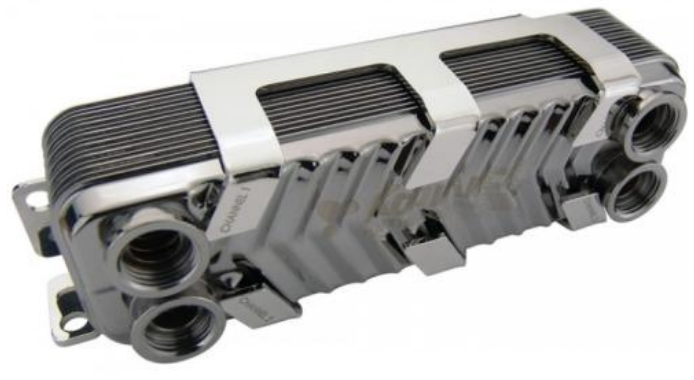

Figure 6: Compact heat exchanger [3]

Table 3.3: Advantages and Disadvantages of compact heat exchanger

\begin{tabular}{|c|c|}
\hline \multicolumn{2}{|c|}{ Compact Heat Exchangers } \\
\hline $\begin{array}{c}\text { Advantages } \\
\end{array}$ & $\begin{array}{c}\text { Disadvantages } \\
\end{array}$ \\
\hline $\begin{array}{c}\text { Low initial purchase cost (plate } \\
\text { type) }\end{array}$ & $\begin{array}{l}\text { Narrower range of allowable } \\
\text { pressures and temperatures }\end{array}$ \\
\hline $\begin{array}{l}\text { Many different configurations } \\
\text { are available (gasket, semi- } \\
\text { welded, welded, spiral) }\end{array}$ & $\begin{array}{l}\text { Subject to plugging/fouling due } \\
\text { to very narrow flow path }\end{array}$ \\
\hline $\begin{array}{l}\text { High heat transfer coefficients ( } 3 \\
\text { or more times greater than for } \\
\text { shell \& tube heat exchangers, due } \\
\text { to much higher wall shear stress) }\end{array}$ & $\begin{array}{l}\text { Gasket units require specialized } \\
\text { opening and closing procedures }\end{array}$ \\
\hline $\begin{array}{l}\text { Tend to exhibit lower fouling } \\
\text { characteristics due to the high } \\
\text { turbulence within the exchanger }\end{array}$ & $\begin{array}{c}\text { Material of construction } \\
\text { selection is critical since wall } \\
\text { thickness very thin (typically } \\
\text { less than } 10 \mathrm{~mm} \text { ) }\end{array}$ \\
\hline $\begin{array}{l}\text { True counter current designs } \\
\text { allow significant temperature } \\
\text { crosses to be achieved }\end{array}$ & \\
\hline $\begin{array}{l}\text { Require small footprint for } \\
\text { installation and have small } \\
\text { volume hold-up }\end{array}$ & \\
\hline
\end{tabular}

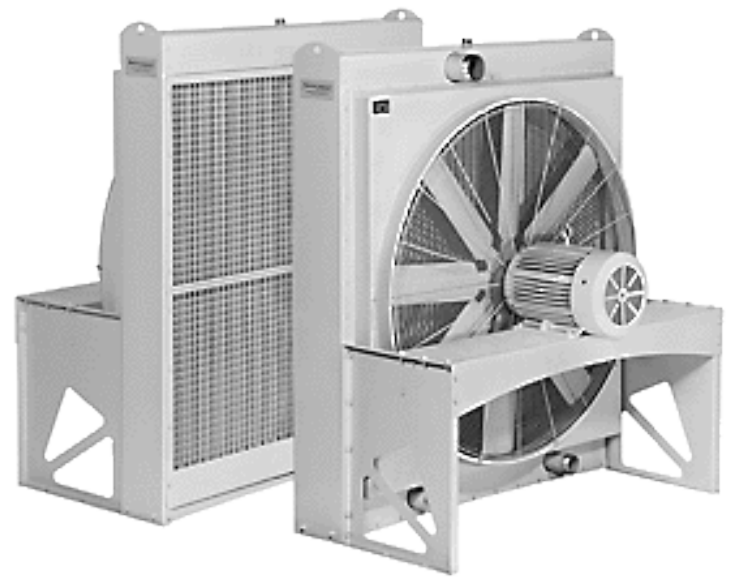

Figure 7: Compact heat exchanger [4]

Table 3.4: Advantages and Disadvantages of air cooled heat exchanger

\begin{tabular}{|c|c|}
\hline \multicolumn{2}{|c|}{ Air Cooled Heat Exchangers } \\
\hline Advantages & Disadvantages \\
\hline $\begin{array}{c}\text { Attractive option for locations } \\
\text { where cooling water is scarce } \\
\text { or expensive to treat }\end{array}$ & High initial purchase cost \\
\hline $\begin{array}{c}\text { Well suited for cooling high } \\
\text { temperature process streams } \\
\text { (above 80oC when using } \\
\text { cooling water should be } \\
\text { avoided) }\end{array}$ & $\begin{array}{c}\text { Require relatively large } \\
\text { footprint }\end{array}$ \\
\hline Low maintenance and & Higher process outlet \\
\hline
\end{tabular}

\begin{tabular}{|c|c|} 
operating costs (typically $30-$ & temperature (10-20 of above \\
$50 \%$ less than cooling water) & the ambient dry bulb
\end{tabular} temperature)

\section{Conclusion}

For the Indian hot conditions, when the temperature will go rise up to $45^{\circ} \mathrm{C}$, and the machines operating with heavy load. The oil temperature will go rise about $50^{\circ} \mathrm{C}$ to $55^{\circ} \mathrm{C}$ which is not desirable for the machine operation as there will be viscosity retention problem and the proper viscosity is vital for the machine operation. That makes important to select a proper size of oil cooler. Because low sized oil cooler will not able to handle heat generation and oversized cooler will be a costly affair.

\section{Acknowledgement}

The research is supported by the L.D.R.P-ITR, Inflibnet and Windsor machines ltd, to acquire enough information about the Plastic Injection Moulding machine, hydraulic system and the Thermal science related to it.

\section{References}

[1] Hassani, H. S., Jafari, A., Mohtasebi, S. S., \&Setayesh, A. M. (2010). Transient heat transfer analysis of hydraulic system for JD 955 harvester combine by finite element method. Journal of Food, Agriculture \& Environment, 8(2), 382-385.

[2] http://www.extranheattransfer.com.au/products/shelland-tube-heat-exchangers/ (Accessed - 02 April 2016)

[3] http://koolance.com/image/cache/data/products/hxp135_p1-700x700.jpg (Accessed - 05 April 2016)

[4] http://coolerindia.com/air-heat-exchanger/air-heatexchangers.jpg(Accessed - 13 April 2016)

[5] http://www.boschrexroth.com/en/xc/industries/machiner $\mathrm{y}$-applications-and-engineering/plastic-machinery-anddie-casting/applications/injection-moldingmachines.htm (Accessed - 24 December 2015)

[6] Floyd Engelking (2014), How to Select and Size Hydraulic-Oil Coolers

[7] Rosato, D. V., \&Rosato, M. G. (2012). Injection molding handbook. Springer Science \& Business Media.

[8] http://windsormachines.com/injection-mouldingmachines.htm[Accessed: December 25,2015]

[9] Ashish.,Wankhede, et al. (2015). Design and Analysis of Hydraulic Oil Cooler by Application of Heat Pipe. In International Journal of Science, Engineering and Technology Research (IJSETR), 3190-3193.

[10] TOMIOKA, K., TANAKA, K., NAGAYAMA, K., \& TOKUDA, K. (2005). Simulation Model of Heat Generation and Transfer in Oil-Hydraulic System. In Proceedings of the JFPS International Symposium on Fluid Power (Vol. 2005, No. 6, pp. 120-125). The Japan Fluid Power System Society.

[11] Totala, N. \& Desai, V. et al. (2014). Manufacturing and comparative analysis of threaded tube heat exchanger with straight tube heat exchanger. International Journal of Engineering and Science, 4(7): 77-85. 


\section{International Journal of Science and Research (IJSR) \\ ISSN (Online): 2319-7064}

Index Copernicus Value (2013): 6.14 | Impact Factor (2015): 6.391

\section{Author Profile}

Sandip Kumar Das received the B.E. degree inMechanical Engineering from Universal College of Engineering and Technology in 2013. He pursuing M.E. in Thermal engineering at L.D.R.PInstitute of Technology and research 2014 - 2016. And he is doing his project work on "Analysis and Enhancement of oil recirculation system for Plastic Injection Moulding Machine" at Windsor Machines Limited. 